\title{
Parametric and Quantitative Analysis on the Development of Shell and Tube Heat Exchanger
}

\section{Olaiya Kamorudeen Adesina ${ }^{1}$, Alabi Ismaila Olanrewaju ${ }^{2}$, Okediji Adebunmi Peter $^{3}$, Alonge Oluwasanmi Iyiola ${ }^{4}$}

\author{
${ }^{1}$ Department of Mechatronics Engineering, The Polytechnic, Ibadan, Nigeria \\ Email: olaiyaexcel@yahoo.com.sg \\ 2, 3,4 Department of Mechanical Engineering, Elizade University Ilara-Mokin, Ondo State, Nigeria \\ 2Email: ismaila.alabi@elizadeuniversity.edu.ng; alabiismy82@gmail.com \\ ${ }^{3}$ Email: adebunmi.okediji@elizadeuniversity.edu.ng \\ ${ }^{4}$ Email: oluwasanmi.alonge@ @elizadeuniversity.edu.ng
}

\begin{abstract}
The importance of mini shell and tube heat exchangers (STHEs) in industrial and other engineering applications cannot be underestimated. Hence, based on the problems associated with the design of STHEs, a mini STHE was developed for transfer of heat between two fluids without mixing on the laboratory scale using locally available materials and technology based on an optimized LMTD technique. The performance of the heat exchanger was assessed and evaluated to determine the optimum combination of design parameters. Copper was utilized for the tube side fluid due to its higher thermal conductivity and anti-microbial property, while galvanized steel was used for the shell side fluid due to its cost and corrosion resistance. Parametric studies were carried out on STHE design parameters to obtain an optimal design for efficiency and effectiveness after relevant design considerations. Experimental results were validated with quantitative models, and it was discovered that both DellBelaware and Engineering Science Data Unit (ESDU) approaches produced the optimal results required for the selection of shell side and tube fluid film coefficients, respectively over other correlations. In conclusion, the values of parameters of interest were also presented after rigorous mathematical calculations at optimal level and probable recommendations were later made.
\end{abstract}

Keywords- Dell-Belaware, ESDU, LMTD, Optimization, STHE.

\section{INTRODUCTION}

Every living thing is equipped in some way or another with devices that tend to enhance or facilitate the flow of heat (Gawande et al., [7]; Ismael and Kumari, [8]) between two or more fluids at different temperatures (Sandeep and Alkesh, [15]) with maximum rate and minimum investment and running cost (Laxnipriya, [12]). These devices are called heat exchangers. They are highly important equipment in any global scenario due to their wide use on both domestic and industrial scales. Heat exchangers are responsible for the greatest energy demand in power generation, waste heat recovery and power plants, as well as industrial processes in manufacturing, air-conditioning, refrigeration, space applications, petrochemical industries (Sandeep and Alkesh, [15]), food industries (Jaydeep et al., [9]), chemical and petrochemical plants, petroleum refineries, natural gas processing, and sewage treatment (Gawande et al., [7]).

In heat exchangers, there are usually no external heat and work interactions. The essence of heat exchanger is to recover or reject heat, or sterilize, pasteurize, fractionate, distill, concentrate, crystallize, or control a process fluid (Dawit, [6). In a few heat exchangers, the fluids exchanging heat are in direct contact. In most heat exchangers, heat transfer between fluids takes place through a separating wall or into and out of a wall in a transient manner. In many heat exchangers, the fluids are separated by a heat transfer surface, and ideally they do not mix or leak (Ramesh and Shah, [14]); as cited by (Dawit, [6]). Heat exchanger may be classified according to the following main criteria (Sandeep and Alkesh, [15]; Laxnipriya, [12]).
i. Arrangements: parallel, counter and cross-flows.
ii. Shell and tube: Recuperators and Regenerators.
iii. Transfer process: Direct contact and Indirect contact.
iv. Geometry of construction: tubes, plates and extended surfaces.
v. Heat transfer mechanisms: single phase and two phase.

Thus, one of the most utilized heat exchangers in industrial and domestic applications is the shell and tube heat exchangers (STHE) which has a wide variety of process and phenomena (Sandeep and Alkesh, [15]); Shell and tube heat exchanger offer great flexibility to meet almost any service requirement and can be designed for high 
pressure relative to the environment and high pressure difference between the fluid streams.

Hence, due to their resistant manufacturing features and design flexibility, shell and tube heat exchangers are the most used heat transfer equipment in industrial processes. They are also easy adaptable to operational conditions. In this way, their design is a very important subject in industrial processes. Nevertheless, some difficulties are found, especially in the shell-side design, because of the complex characteristics of heat transfer and pressure drop (Lokhande and Kumar, [13]). In reality, shell and tube heat exchanger is not suitable for use in aircraft and automotive purposes because the size is relatively large and also weighty (Kamaruddin, [11]). In this work, the main focus is to design a mini shell and tube heat exchanger on a laboratory scale for experimental purposes. Those difficulties reported earlier are examined to come up with a better facility that will be operating at minimal cost under optimized conditions.

Thus, this work is aimed at developing a prototype shell and tube heat exchanger using locally available technology and materials via design based on optimal combination of parameters using LMTD technique, fabrication, as well as, performance evaluation of the facility. This work gives a general overview of heat exchanger together with the exposure on the basic principle and analysis of shell and tube heat exchanger using the LMTD software. Also, it enhances the practical knowledge of machine assembling.

\section{DESCRIPTION OF SHELL AND TUBE HEAT EXCHANGER (STHE)}

According to Alok et al., [2], shell and tube heat exchangers are classified upon the following factors: construction, flow arrangement, number of shells, and contact between the processing streams, compactness and heat transfer mechanism. Jurandir [10] classified heat exchanger into two. The first being called 'the recuperative type', in which heat are exchanged on either side of a dividing wall by fluids, while the second is 'the regenerative type', in which hot and cold fluids are in the same space which contain a matrix of materials which work alternately as source for heat flow. However, irrespective of the classifications and types of heat exchangers available in the industry, the Shell and Tube Type heat exchanger is probably the most used and widespread type of the heat exchanger's classification (Vindhya et al., [16]).

Shell and tube heat exchanger is built of a bundle of round tubes mounted in a large cylindrical shell with the tube axis parallel to the shell to transfer the heat between the two fluids. They provide relatively large ratio of heat transfer area to volume and weight and they can be easily cleaned. They offer greater flexibility to meet almost any service requirement they can be designed for high pressure relative to the environment and high pressure difference between the fluid streams (Sandeep, and Alkesh, [15]). Shell and tube type of heat exchanger is said to have originated from the jacketed coil distiller. It is however majorly used in heavy industries as well as in residential hot water heating system (Alfred, [1]), cooling of hydraulic fluids and oil in engines, and other mediums such as swimming pool water or charge air (Asawari, [4]). Perhaps the most common type of heat exchanger in industrial applications is the shell-and-tube heat exchanger, shown in Figure 1. Shell-and-tube heat exchangers contain a large number of tubes (sometimes several hundred) packed in a shell with their axes parallel to that of the shell. Heat transfer takes place as one fluid flows inside the tubes while the other fluid flows outside the tubes through the shell. Baffles are commonly placed in the shell to force the shell-side fluid to flow across the shell to enhance heat transfer and to maintain uniform spacing between the tubes. Despite their widespread use, shell and tube heat exchangers are not suitable for use in automotive and aircraft applications because of their relatively large size and weight. Note that the tubes in a shell-and-tube heat exchanger open to some large flow areas called headers at both ends of the shell, where the tube-side fluid accumulates before entering the tubes and after leaving them.

Shell-and-tube heat exchangers are further classified according to the number of shell and tube passes involved. Heat exchangers in which all the tubes make one U-turn in the shell as shown in figure $2 \mathrm{a}$ are called one-shell-pass and two - tube - passes heat exchangers. Likewise, a heat exchanger that involves two passes in the shell and four passes in the tubes as shown in figure $2 b$ is called a twoshell-passes and four-tube-passes heat exchanger (Cengel, [5]).

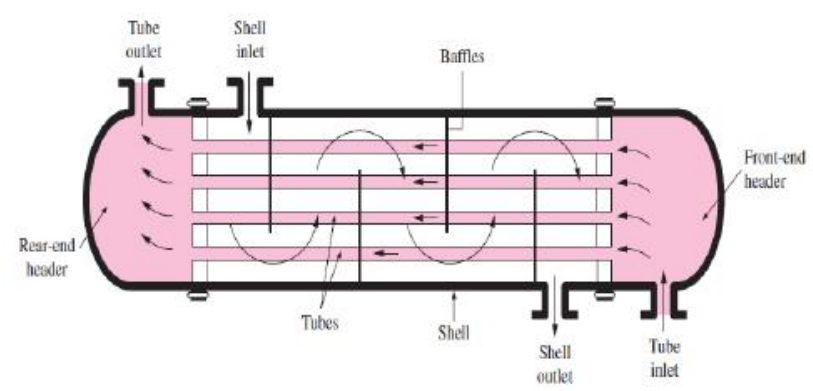

Fig.1: The schematic of a shell-and-tube heat exchanger (Cengel, [5]). 


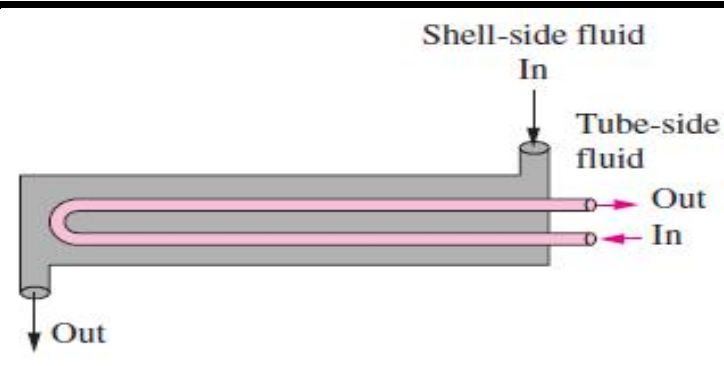

(a) One-shell pass and two-tube passes

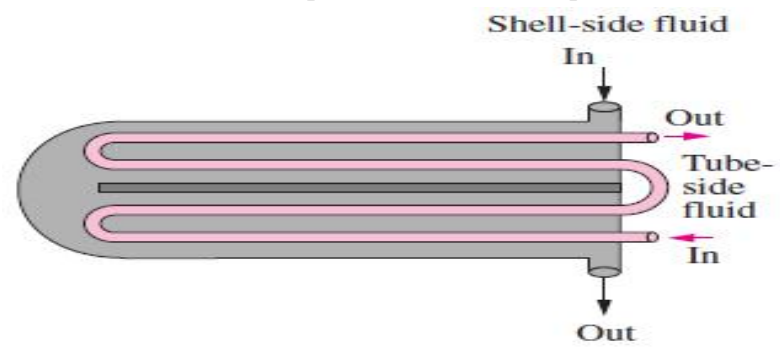

(b) Two-shell pass and four-tube passes

Fig. 2: Classification of shell and tube heat exchanger (Cengel, [5])

\section{METHODOLOGY}

\subsection{Materials}

For the development of a shell and tube heat exchanger, the materials utilized were considered based on the factors in figure 3. Heat exchanger tubes are available in variety of materials, which include both ferrous and non-ferrous materials such as carbon steel, stainless steel, copper, admiralty brass, 90-10 copper-nickel, etc. They are available in a number of wall thickness defined by BWG (Ismael and Kumari, [8]). Galvanized steel was used to construct the shell and the two tube sheets/plates. This was because galvanized steel has high resistant to corrosion. Similarly, the main frame was made up of mild steel because of its strength and rigidity to support load and weight of the machine during operation. The tubes used in this project were made of copper due to its high thermal conductivity and anti-microbial property.

\subsection{Method}

In the present work, the methodology used in the design of the heat exchanger is studied and presented. The thermal design involves the calculation of shell side and tube side heat transfer coefficients, heat transfer surface area and pressure drops on the shell and tube sides. The mechanical design involves the calculations of thickness of pressure parts of the heat exchanger such as the shell, channel, tube etc. to evaluate the rigidity of part under design pressures.

\subsubsection{Description of the project/Working Principle}

i. The principle of operation is simple enough, two fluids of different temperatures are brought into close contact but they are not mixing with each other. ii. One fluid runs through the tube, and another fluid flows over the tube (through the shell) to transfer heat between the two fluids.

iii. The hot water run through the shell while glycerin run through the tube side. In order to transfer heat efficiently, a large heat transfer area were used, so there are many tubes.

iv. The temperatures of the two fluids tend to be equal. The heat is simply exchanged from one fluid to another and vice versa. No energy is added or removed.

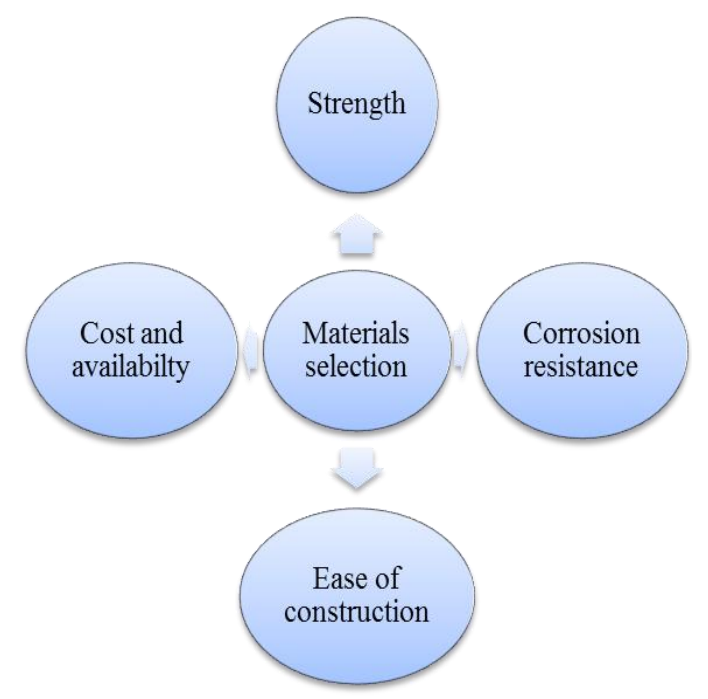

Fig. 3: Materials Selection

3.2.2 Component part of a shell and tube heat exchanger The following are the component parts of a shell and tube heat exchanger designed:

1. Tubes: The tubes are the basic component of the shell and tube exchanger, providing the heat transfer surface between one fluid flowing inside the tube and the other fluid flowing across the outside of the tubes. The tubes utilized in this work were welded and made of copper due to its high thermal conductivity. The tubes are 1000 $\mathrm{mm}$ and $\phi 12.7 \mathrm{~mm}$ each.

2. Tube Pitch: The tube pitch shown in figure 4 is the shortest distance between two adjacent tubes. Tube holes cannot be drilled very close together since too small width of metal between the adjacent tubes structurally weakens the tube sheet. The shortest distance between the two tube holes is the clearance (Ismael and Kumari, [8]). In this work a triangular pitch was adopted because it provides a more robust tube sheet construction 


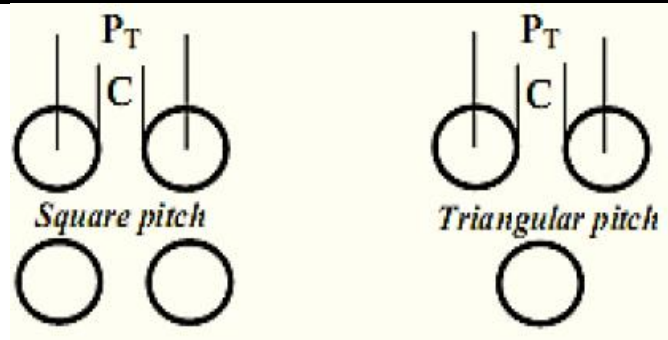

Fig. 4: Tube Pitch $\left(P_{T}\right)$

3. Tube Sheet/plates: They are used to hold the tubes at the ends. The tube sheet used in the construction is made of circular metal (galvanized steel) plate with holes drilled through for the desired tube pattern, holes for the tie rods, grooves for the gaskets and bolt holes for flanges to the shell.

4. Baffles: It is apparent that higher heat transfer coefficient results when the liquid is maintained in the state of turbulence. To induce turbulence outside the tube it is customary to employ baffles, which cause the liquid to flow through the shell at right angles to the exit of the tubes. Baffles serve two functions: Most importantly, they support the tubes in the proper position during assembly and operation and prevent vibration of the tubes caused by flow-induced eddies, and secondly, they guide the shell-side flow back and forth across the tube field, increasing the velocity and the heat transfer coefficient (Jaydeep et al., [9]). In this project, the baffles machined were made from galvanized steel which is compatible with the shell side fluid. The tube holes must be precise enough to allow easy assembly and field tube replacement, yet minimize the chance of fluid flowing between the tube wall and baffle hole, resulting in reduced thermal performance and increased potential for tube wall cutting from vibration. Baffles do not extend edge to edge, but have a cut that allows shell side fluid to flow to the next baffled chamber. For most liquid applications, the cuts areas represent $20-25 \%$ of the shell diameter. In this project cuts areas of $25 \%$ was adopted.

5. Nozzles: The entrance and exit ports for the shell fluid and tube fluid are referred to as "Nozzles". These nozzles are pipes of constant cross section welded to the shell and channels. They are used to distribute or collect the fluid uniformly on shell and tube sides.

6. Front-End And Rear End Covers: They are containers for tube fluids for every pass. In many rear end head designs, a provision has been made to take care of thermal expansion of whole tube bundle. The front-end head is stationery while the rear end head could be either stationary or floating depending upon the thermal stresses between the tubes and shell. But in this project both ends are stationary.

7. Tie Rods and Spacers: Tie rods and spacers are other equivalent means of tying baffle system together. They are provided to retain all transverse baffles and tube support plates securely in position. They serve two purposes; one to maintain the spacing between the baffles and second function is to reduce the fluid by-passing.

8. Shell: The cylindrical shell made of rolled galvanized steel plate carries flanged connection for water inlet, water outlet, plug and couplings for shell drain and vent. Suitable provisions are made for pressure and temperature measurement. In this project the shell which is cylindrical was produced from the rolling machine.

9. Fluid Chambers: Both the inlet and outlet and rear end fluid chambers are fabricated from rolled galvanized steel plate and are of adequate proportions to minimize pressure drop and turbulence. The inlet and outlet fluid chamber carries water and inspection cover was divided internally into inlet and outlet chambers, each having a flanged connection. The rear end fluid chamber consists of a simple dished cover or a flat end cover. If the water passes are more than two it is divided accordingly.

10. AT-380 AC 220-240V 15W Submersible Water Pump Aquarium Fountain Pond Pump: A submersible pump shown in figure 5 has a sealed motor closely coupled to the pump body and pushes water to the surface. It functions via its assembly that is wholly submerged in the fluid to be pumped whereas a centrifugal pump uses a rotating impeller to increase pressure of a fluid.

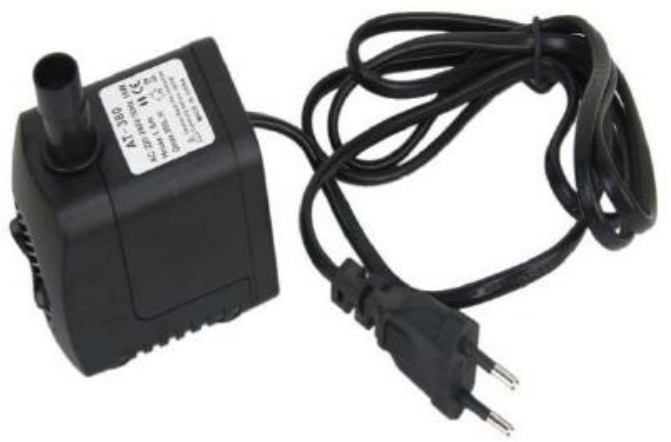

Fig. 5: Submersible Water Pump

11. 12V $45 \mathrm{~W}$ micro diaphragm pump discharge pressure backflow PLD-1206 thread water 
pump wash car: "Brandy" brand DC microdiaphragm pump shown in figure 6 is a selfsuction pump with the advantages of chemical pump, using a variety of imported materials synthesis, corrosion resistant, with self-priming function, thermal protection, smooth operation, can long time continuous idling, can long time continuous load operation, small volume, low current, high pressure, low noise, the use of the advantages of long service life, exquisite design, high quality and inexpensive, with oil resistant, heat resistant, acid and alkali resistance, corrosion resistance, chemical resistance properties. Pump body and motor separation, the pump body without mechanical components, no wear. The surface pump used has the following specifications: Rated voltage $=12 \mathrm{~V}$ DC, Rated power $=45 \mathrm{~W}$, Maximum pressure $=1 \mathrm{MPa}$, Flow rate $=4$ litres $/ \mathrm{min}$, Suction diameter 9.2 $\mathrm{mm}$, Discharge diameter $=9.2 \mathrm{~mm}$.

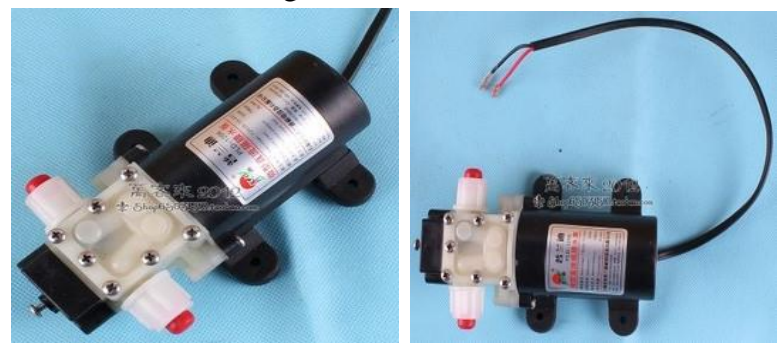

Fig. 6: A Micro-diaphragm pump (self-suction Pump)

\subsubsection{Design Consideration}

The optimum thermal design of a shell and tube heat exchanger involves the consideration of many interacting design parameters which can be summarized as shown in figure 7 .

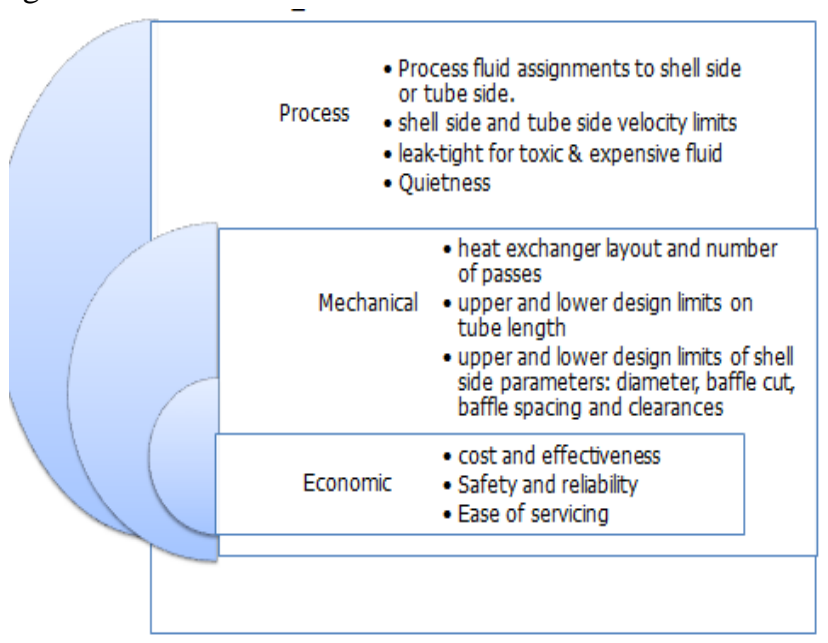

Fig. 7: Design consideration

Highest thermal performance is the key factor determining the efficiency of any Shell and Tube Heat Exchanger.
Hence, in the design of Heat Exchanger, the foremost considerations should be given to the cost and effectiveness so as to improve its efficiency (Arjun and Gopu, [3]).

\subsection{Design Calculations}

\subsection{1: Assumptions}

A selected shell and tube heat exchanger must satisfy the process requirements with the allowable pressure drops until the next scheduled cleaning of plant. The methodology to evaluate thermal parameters is explained with suitable assumptions. The following are the major assumptions made for the pressure drop analysis;

1) The operating or Flow condition is steady and isothermal, and fluid properties are independents of time.

2) Fluid density is dependent on the local temperature only or is treated as constant.

3) The pressure at a point in the fluid is independent of direction.

4) Body force is caused only by gravity.

5) There are no energy sink or sources along streamline; flow stream mechanical energy dissipation is idealized as zero. i.e. Changes from K.E to P.E of fluid streams are negligible

6) The friction factor is considered as constant with passage flow length.

7) The heat exchanger is well insulated so that heat loss is negligible and thus heat transfers from hot to cold fluids are equal.

8) Heat transfer coefficient and fouling factors are constant and uniform

9) Thermal resistance of the inner tube is negligible, since the tube is thin walled and highly conductive.

\subsubsection{Modeling Procedures and Design Calculations}

\section{A. Modeling Procedures}

The mathematical model has been constructed considering the principles of heat transfer and fluid mechanics. Shell and tube heat exchangers are designed normally by using Nusselts, Eissenberg, McNaught, Colbalt, Kern's, Taborek, Chemstations, VDI film and Bell-Delaware methods, as well as other correlations like Petukov, Chaddock and Chato adaptation, Duckler (downflow) and Hewitt (upflow) adaptations, and Mikheev correlation etc. However, either Kern's method or Bell-Delaware method are mostly adopted in the design of a shell and tube heat exchanger (STHE). The steps of designing a typical shell and tube heat exchanger are described in figure 8 . 
$h_{t}=\frac{N_{t} k_{t}}{d_{t i}}=\frac{0.027 k_{t}}{d_{t i}} R_{e}^{0.8} \operatorname{Pr}^{0.33}$

(6)

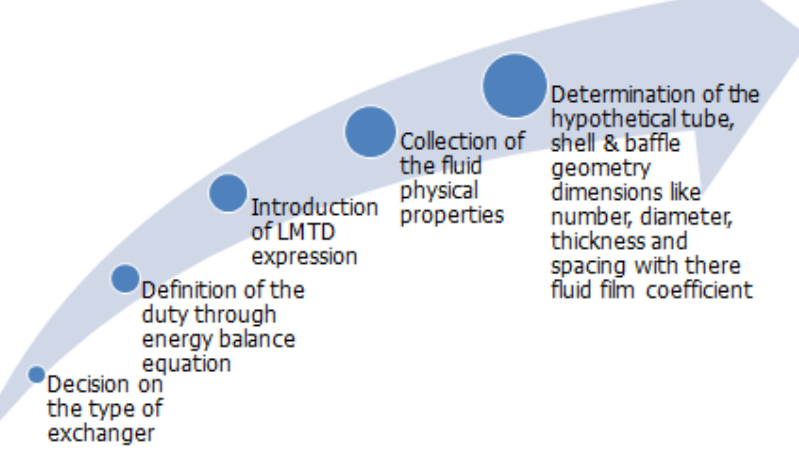

Fig. 8: Modeling Procedure

B. Determination of heat transfer coefficient on the inner and outer surface of the tubes using the above methods to optimized the design

1. Shell-side Transfer Coefficient $\left(h_{0}=h_{s}\right)$

i. Kern's Method

$$
\begin{gathered}
d_{e}=\frac{4}{\pi d_{t 0}}\left[p_{t}^{2}-\frac{\pi d_{t 0}^{2}}{4}\right] \\
R e_{s}=\frac{M_{s}}{A_{s}} \times \frac{D_{e}}{\mu_{s}} \\
N_{u}=\frac{h_{s} d_{e}}{k_{s}}=0.36 R_{e}{ }^{0.55} \operatorname{Pr}^{\frac{1}{3}} \\
h_{s}=\frac{N_{s} k_{s}}{d_{e}}=\frac{0.36 k s}{d_{e}} R_{e}{ }^{0.55} \operatorname{Pr}^{1 / 3}
\end{gathered}
$$

ii. Taborek Method

$$
\begin{array}{r}
R_{e s}=\frac{m_{s}}{A_{s}} \times \frac{d_{t 0}}{\mu_{s}} \\
h_{s}=\frac{0.2 k s}{d_{t 0}} R_{e}{ }^{0.6} \mathrm{Pr}^{0.4}
\end{array}
$$

iii. Bell-Delaware Method

$$
\begin{gathered}
h_{s}=j_{i} C P_{S}\left(\frac{M_{s}}{A_{s}}\right)\left[\frac{K_{s}}{C P_{s} \mu_{s}}\right]^{2 / 3}\left[\frac{\mu_{t}}{\mu_{s}}\right]^{0.14} \\
\text { Neglecting } \frac{\mu_{t}}{\mu_{s}} \approx 1 \\
J_{i}=0.37 R_{e s}{ }^{-0.395} \\
h_{s}=j_{i} c_{p s}\left(\frac{m_{s}}{A_{s}}\right)\left[\frac{K_{s}}{c_{p s} \mu_{s}}\right]^{2 / 3}
\end{gathered}
$$

2. Tube side heat transfer coefficient

i. Petikhov - Kiwlov Correlation

$$
\begin{gathered}
f=\left[\left[1.58 \ln \left(R_{e t}\right)\right]-(3.28)\right]^{-2} \\
R_{e t}=\frac{\ell_{t} U_{m} d_{t i}}{U_{t}}
\end{gathered}
$$

$$
N u_{t}=\frac{(f / 2) R e_{t} P r_{t}}{(1.07)+(12.7)(f / 2)\left(P r_{t}{ }^{1 / 2}-1\right)}
$$

$h_{t}=h_{i}=\frac{N u_{t} k_{t}}{d_{t i}}=\frac{k_{t}}{d_{t i}} \frac{(f / 2) R e_{t} P r_{t}}{(1.07)+(12.7)(f / 2)\left(P r_{t}{ }^{1 / 2}-1\right)}$

ii. Seider-Tate Equation or Colburn Equation

$h_{t}=\frac{N_{t} k_{t}}{d_{t i}}=\frac{0.023 k_{t}}{d_{t i}} R_{e}{ }^{0.8} \mathrm{Pr}^{0.33}$

iii. Kern Techniques iv. Engineering Sciences Data Unit (ESDU)

\section{Method}

$h_{t}=\frac{N_{t} k_{t}}{d_{t i}}=\frac{0.0225 k_{t}}{d_{t i}} R_{e} e^{0.795} \operatorname{Pr}^{0.495} \exp \left[-0.0225(\ln P r)^{2}\right]$

3. Calculation on the value of the overall coefficient, $\mathrm{U}$.

$$
\frac{1}{\mu_{0}}=\frac{1}{h_{0}}+\frac{1}{h_{i}} \frac{d_{0}}{d_{i}}+\frac{r_{0} \ln \left(r_{0} / r_{i}\right)}{k_{w}}
$$

4. Determination of the area required of the heat exchanger (on the basis of assumed $\mathrm{U}_{0}$ ) using

$$
Q=U A \Delta T L_{m},
$$

5. Pressure Drop in STHE

i. Tube Side Pressure Drop: The tube side pressure drop can be calculated by knowing the number of tube passes (Np) and length (L) of heat exchanger; the pressure drop for the tube side fluid is given by equation

$$
\Delta P_{t}=4 f \frac{L N_{p}}{d_{t i}} \rho \frac{u_{m}^{2}}{2}
$$

The change of direction in the passes introduction in the passes introduction an additional pressure drop due to sudden expansions and contractions that the tube fluid experiences during a return that is accounted for allowing four velocity head per pass

$$
\Delta P_{t}=4 N_{p} \frac{\rho u_{m}^{2}}{2}
$$

The total pressure drop of the side becomes:

$$
\Delta P_{t}=\left(4 f \frac{L N_{p}}{d_{t i}}+4 N_{p}\right) \rho \frac{u_{m}^{2}}{2}
$$

ii. Shell Side Pressure Drop: The shell side pressure drop depends on the number of tubes, the number of times the fluid passes the tube bundle between the baffles and the length of each crossing. The pressure drop on the shell side is calculated by the following expression (Sandeep, and Alkesh, [15]):

$$
\Delta P_{s}=f \frac{\rho u_{m}^{2}\left(N_{b}+1\right) d_{s}}{2 d_{t o} \phi_{s}}
$$

Where,

$$
\phi_{s}=\left(\mu_{t}+\mu_{s}\right) 0.14
$$

$\mathrm{N}_{\mathrm{b}}=$ Number of baffles

$\left(\mathrm{N}_{\mathrm{b}}+1\right)=$ Number of times fluid passes to the tube bundle

Friction factor (f) calculated from:

$$
f=\exp \left(0.576-0.19 \ln R e_{s}\right)
$$

Where

$$
400<R e_{s}=\frac{\rho_{s} u_{m} d_{s}}{\mu_{s}} \leq 1 \times 10^{6}
$$


The correlation has been tested based on data obtained on actual exchangers. The friction coefficient also takes entrance and exit losses into account (Sandeep, and Alkesh, [15]).

\section{$3.4 \quad$ Testing}

\subsubsection{Field Test}

The shell and tube heat exchanger (STHE) shown in figure 9 was subjected to field test after fabrication. The flow arrangement adopted for the design is the cross flow due to the greater log mean temperature it offers. One yard of $1 \frac{114}{4}$ diameter hose was used to convey the fluid at the tube inlet and clipped to ensure the hose is firmly fitted to the heat exchanger inlet port. The hose connected to the tube inlet in turn connected to the outlet of the submersible pump submerged in the glycerin for easy flow of the fluid (glycerin) into the heat exchanger, while the hose connected to the outlet of the shell side fluid (hot water) was inserted in the retaining container. Similarly, another $1 \frac{1}{4}$ one yard hose was connected to the inlet of the shell side fluid (hot water) and outlet of the cold side fluid which are gripped with a hose clip. The inlet of the shell side fluid (hot water) was connected to the outlet of the surface pump while the inlet of the pump was dipped in the hot water. The submersible pump which utilizes Alternating current (AC) was plugged into the AC socket while the surface pump was powered with a $12 \mathrm{v}$ battery.

The hot water used for the experiment was obtained from a 25 litres cooking pot placed on the gas cooker. The observed temperature of the shell side fluid was $100^{\circ} \mathrm{c}$, while that of the tube fluid side (cold fluid) was $26^{\circ} \mathrm{c}$ before been allowed to flow into the heat exchanger. The temperature measurements were taken with the aid of an analogue thermometer.

At the end of the experiment, the heat transferred to the cold fluid increased by $6^{\circ} \mathrm{c}$ while that of the hot fluid reduced to $60^{\circ} \mathrm{c}$.

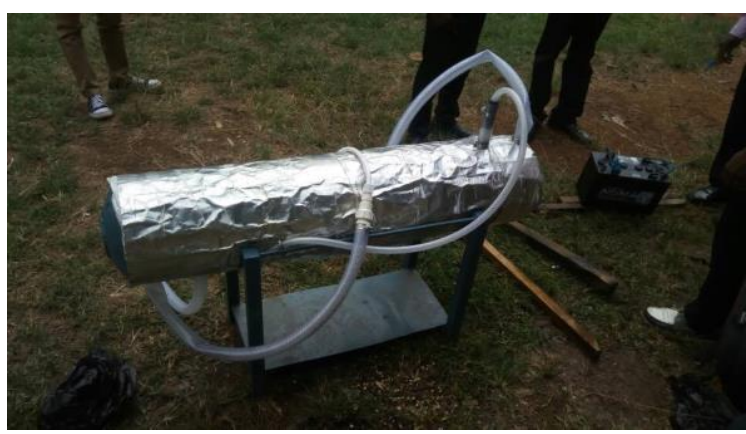

Fig. 9: Field Test Demostration of the STHE

\subsubsection{Laboratory Test}

The shell and tube heat exchanger (STHE) was also subjected to laboratory test after field test. The essence of this is to test the STHE on a large scale. The compartment carrying hot fluid was connected to the boiler so that there will be constant supply of hot fluid to the heat exchanger, but could not be achieved due to the ineffectiveness of that machine (boiler). The STHE fabricated demonstration when connected to the faulty boiler is presented in figure 10 .

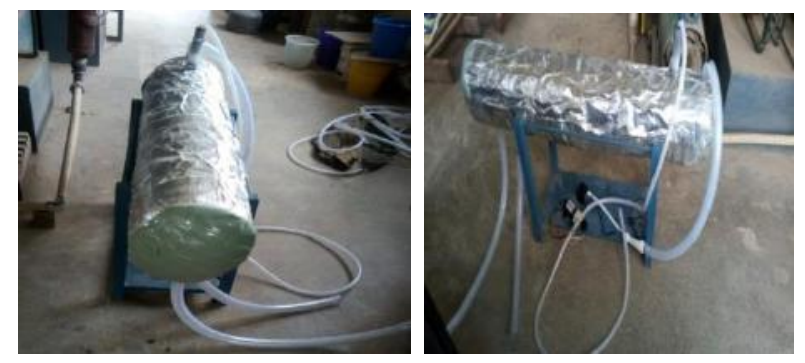

Fig. 10: Laboratory Test Demostration of the STHE

\section{RESULTS AND DISCUSSION}

4.1 Experimental Results

The results obtained from the experimental results are presented below:

Shell side fluid - Hot water

Tube side fluid - Glycerin

Inlet temperature of hot water, $T_{h 1}=100^{\circ} \mathrm{C}$

Outlet temperature of hot water, $T_{h 2}=90^{\circ} \mathrm{C}$

Inlet temperature of Glycerin, $T_{c 1}=26^{\circ} \mathrm{C}$

Outlet temperature of Glycerin, $T_{c 2}=$ ?

Mass flow rate of Glycerin, $m_{t}=0.28 \mathrm{~kg} / \mathrm{s} \quad m_{c}$

Mass flow rate of hot water, $m_{s}=0.07 \mathrm{~kg} / \mathrm{s} \quad-m_{h}$

Thermal conducting of the material, $\mathrm{k}_{\mathrm{w}}=16.26 \mathrm{~W} / \mathrm{m}^{0} \mathrm{C}$

The maximum flow rate through the tube, $U_{\max }=$ $0.82 \mathrm{~mm} / \mathrm{s}$

Table 1: Thermal properties of shell-side fluid @ average temperature $=\frac{T_{h 1}+T_{h 2}}{2}$

\begin{tabular}{|c|c|c|c|c|c|c|c|c|}
\hline \multirow{3}{*}{$\begin{array}{l}\mathbf{S} \\
/ \\
\mathbf{N}\end{array}$} & \multirow{2}{*}{$\begin{array}{l}\text { Prope } \\
\text { rty }\end{array}$} & \multirow{2}{*}{$\begin{array}{l}\text { Sy } \\
\text { mb }\end{array}$} & \multirow[t]{2}{*}{ Unit } & \multicolumn{5}{|c|}{ Values } \\
\hline & & & & 95 & 90 & 85 & 80 & 75 \\
\hline & & ol & & $\left({ }^{0} \mathrm{C}\right)$ & $\left({ }^{0} \mathrm{C}\right.$ & $\left({ }^{0} \mathrm{C}\right)$ & $\left({ }^{0} \mathrm{C}\right)$ & $\left({ }^{0} \mathrm{C}\right)$ \\
\hline & & & & & ) & & & \\
\hline \multirow[t]{3}{*}{1} & Spec. & $\mathrm{Cp}$ & $\mathrm{j} / \mathrm{kg} /$ & 4212 & 420 & 4201 & 4197 & 4193 \\
\hline & heat & & $\mathrm{k}$ & & 6 & & & \\
\hline & & & & & & & & \\
\hline \multirow[t]{4}{*}{2} & Therm & K & $\mathrm{j} / \mathrm{kgk}$ & 0.67 & 0.6 & 0.67 & 0.67 & 0.66 \\
\hline & & & & 7 & 75 & 3 & 0 & 7 \\
\hline & condu & & & & & & & \\
\hline & ctivity & & & & & & & \\
\hline \multirow[t]{2}{*}{3} & Pradtl & $\operatorname{Pr}$ & & 1.85 & 1.9 & 2.08 & 2.22 & 2.38 \\
\hline & No. & & & & 6 & & & \\
\hline \multirow[t]{2}{*}{4} & Densit & $\ell$ & $\mathrm{Kg} /$ & 961. & 965 & 968. & 971. & 974. \\
\hline & $\mathrm{y}$ & & $\mathrm{m}^{3}$ & 5 & .3 & 1 & 8 & 7 \\
\hline \multirow[t]{3}{*}{5} & Viscos & $\mu$ & $\mathrm{Kg} /$ & 0.29 & 0.3 & 0.33 & 0.35 & 0.37 \\
\hline & ity & & $\mathrm{m} . \mathrm{s}$ & 8 E- & 15 & $3 \mathrm{E}-$ & $5 \mathrm{E}-$ & 8 E- \\
\hline & & & & 3 & E-3 & 3 & 3 & 3 \\
\hline
\end{tabular}


Table.2: Thermal and physical properties of tube side fluid@260 $\mathrm{C}$

$\begin{array}{llcl}\text { S/No. } & \text { Property } & \text { Symbol } & \text { Value } \\ 1 & \text { Spec. heat cap. } & \mathrm{Cp} & 2416 \mathrm{j} / \mathrm{kg} / \mathrm{k} \\ 2 & \begin{array}{l}\text { Thermal } \\ \text { conductivity }\end{array} & \mathrm{K} & 0.2860 \\ & \text { Pradtl No. } & \mathrm{wr} / \mathrm{m} / \mathrm{k} & 8.392 \\ 4 & \text { Density } & \ell & 1261 \mathrm{Kg} / \mathrm{m}^{3} \\ 4 & \text { Viscosity } & \mu & 0.9934 \\ 5 & & & \mathrm{Kg} / \mathrm{m} . \mathrm{s}\end{array}$

4.2 Modeling Results

Fig. 11 showed the result obtained from the plot of shell fluid film coefficient $\left(h_{0}\right)$ against Logarithmic Mean Temperature Difference (LMTD). It was observed that there is a direct relationship between $h_{o}$ and the LMTD. It was also observed that $h_{o}$ decreases as the shell diameters decreases.

It was observed from fig. 12 that as the shell diameter $\left(d_{s}\right)$ increases, both the overall heat transfer coefficient $\left(U_{0}\right)$ and tube fluid film coefficient $\left(\mathrm{h}_{\mathrm{i}}\right)$ decreases.

It was observed from fig. 13 that as the LMTD increases the correction factor, irrespective of the tube sizes decreases. It was also discovered that the correction factor increases as the tube diameters increases.

\section{CONCLUSION}

The importance of mini shell and tube heat exchangers in industrial and other engineering applications cannot be underestimated. Hence in this project, a mini and shell and tube heat exchanger was developed on the laboratory scale using an optimized LMTD technique before embarking on the design and fabrication. The performance of the heat exchanger was assessed and evaluated to determine the optimum combination of design parameters for the transfer of heat between the two fluids involved in the STHE without mixing. It was discovered from the obtained results that the Bell-Delaware correlation produced the optimal value of shell fluid film coefficient over the other correlation techniques at any parametric iterations. Kern technique was the closest with correction factors between 0.8440 and 0.9850 . There was also an inverse relationship between the shell fluid film coefficient and heat transfer rate. Though, irrespective of the shell diameters, the heat transfer rate is constant. But there is an inverse relationship between the LMTD and the heat transfer rate under any shell design parameters. In addition, there was a direct relationship between $h_{o}$ and the LMTD. While $h_{o}$ decreases as the shell diameters decreases. It was observed that as the shell diameter $\left(d_{s}\right)$ increases, both the overall heat transfer coefficient $\left(\mathrm{U}_{\mathrm{o}}\right)$ and tube fluid film coefficient $\left(\mathrm{h}_{\mathrm{i}}\right)$ decreases. The LMTD increases, the correction factor, irrespective of the tube sizes decreases. It was also discovered that the correction factor increases as the tube diameters increases. In conclusion, the Values of parameters of interest were also presented after rigorous mathematical calculations at optimal level. It was also discovered that Engineering Science Data Unit (ESDU) approach produced the optimal results required for the selection of tube fluid film coefficient over other correlations.

The design techniques and procedure adopted in this research work should be strictly adhere to by the Thermal and Fluid Engineers that are interested in the design of shell and tube heat exchangers (STHE) in order to come up with an optimum results. Other correlation techniques required for the determination of shell and tube fluid film transfer coefficients should be considered in the future research since this work is limited to only few.

\section{REFERENCES}

[1] Alfred, M.K. (2015). Article in Applied Thermal Engineering. Retrieved from www.researchgate.net/publication/279178955

[2] Alok, S., Prakash, K. and Deo, R.T. (2015). Design Procedure of Shell and Tube Heat Exchanger vol. 3, issue 12, pp. 116-119.Retrieved from www.erpublication.org

[3] Arjun, K.S. and Gopu, K.B. (2014) Design of Shell and Tube Heat Exchanger Using Computational Fluid Dynamics Tools, Research Journal of Engineering Sciences, Vol. 3(7), pp. 8-16

[4] Asawari, B. (2016). An Overview of Shell and Tube Heat Exchanger Performance, International Journal of Research in Aeronautical and Mechanical Engineering, Vol.4 Issue 2, pp. 58-66.

[5] Cengel, Y.O. (2003) Heat Transfer A practical Approach (second edition), McGraw-Hill, pp. 667716

[6] Dawit, B. (2014). Design and Development of Shell and Tube Heat Exchanger for Harar Brewery Company Pasteurizer Application (Mechanical and Thermal Design), Volume-03, Issue-10, pp. 99-109 www.ajer.org

[7] Gawande, S.H., Wankhede, S.D., Yeerrawar, R.N, Sonawane, V.J. and Ubarhande, V.B. (2012). Design and Development of Shell and Tube Heat Exchanger for Beverage. Mordern Mechanical Engineering, vol. 2, pp121-125. Retrived from http://dx.doi.org/10.4236/mne.2012.24015

[8] Ismael, B.R. and Kumari, A. (2014) Design and Analysis of Heat Exchanger, International Journal of 
Scientific Engineering and Technology Research, Vol. 03, Issue 20 pp. 4181-4187.

[9] Jaydeep, B., Abhesinh, P. and Mahesh, V. (2013). A project Report on Designing and Analysis of Shell and Tube Heat Exchanger, pp. 1-36.

[10] Jurandir, P.P. (2012) Shell and Tube Heat Exchangers Basic Calculations, pp. 1-35. Retrieved from www.PDHonline.org

[11] Kamaruddin, R. (2010). Report on Design of a Small Heat Exchanger (Shell-And-Tube Type), pp. 1-11.

[12] Laxnipriya, S. (2014). CFD Analysis of Heat transfer in a Helical coil Heat Exchanger with constant Wall Heat transfer Coefficient, pp. 1-40.

[13] Lokhande, H.K.. and Kumar, P.V. (2013). Review Paper on Design \& Analysis for Shell \& Tube Evaporator for Dairy Application, Vol 3. pp. 117-118. Retrieved from www.ijetae.com

[14] Ramesh, K. and Shah, D. P. (2003). Fundamentals of Heat Exchanger Design. New Jercy

[15] Sandeep, K.P. and Alkesh, M.M. (2012). Shell and Tube Heat Exchanger Thermal Design with Optimization of Mass flow rate and Baffle Spacing. Patel et al, International Journal of Advanced Engineering Research and Studies, vol. 2, pp. 130135.

[16] Vindhya, V.P.D., Raj, R.V., Piyush, S.V. and Srivastava, A. K. (2014). Steady State Thermal Analysis of Shell and Tube Type Heat Exchanger to Demonstrate the Heat Transfer Capabilities of Various Thermal Materials using Ansys, Global Journal of Researches in Engineering: A Mechanical and Mechanics Engineering Volume 14 Issue 4 Version 1.0, pp. 24-30.

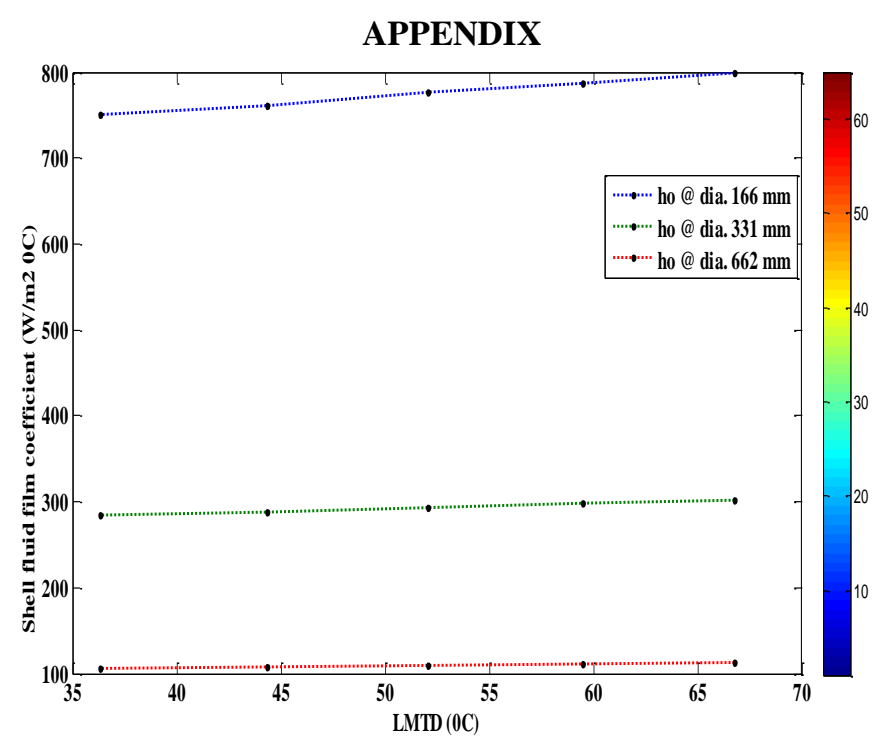

Fig. 11: Shell fluid film coefficient against LMTD

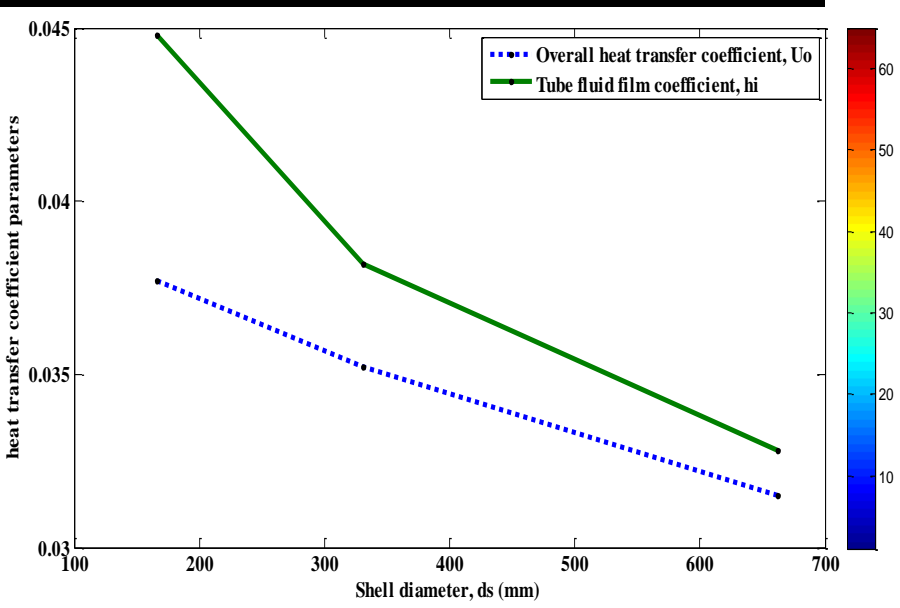

Fig. 12: Heat transfer coefficient parameters against Shell diameters

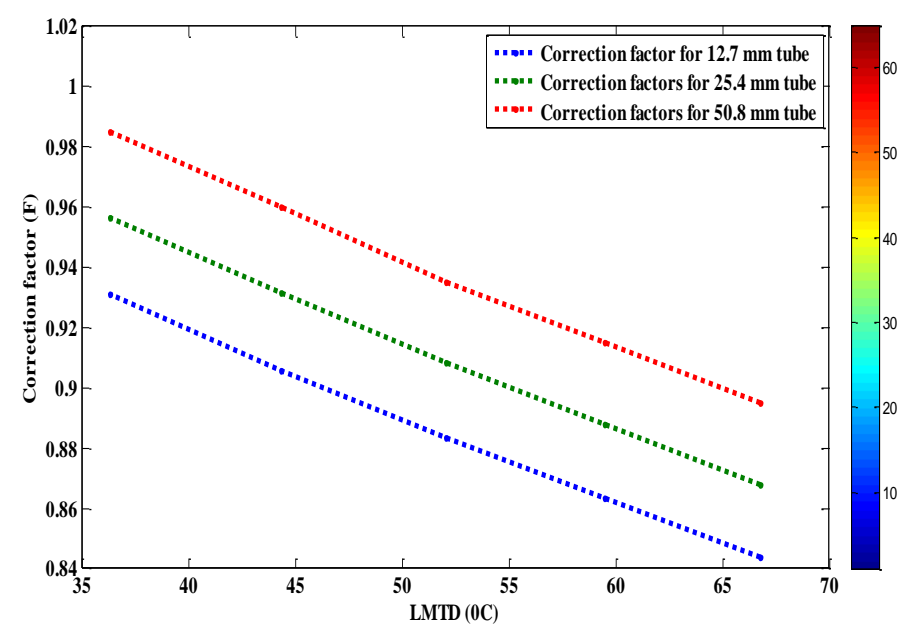

Fig. 13: Correction factor against LMTD 